\title{
VIABILIDADE DE APLICAÇÃO E REAPROVEITAMENTO DE ENERGIA SOLAR CONECTADA À REDE ELÉTRICA PARA UMA RESIDÊNCIA UNIFAMILIAR
}

\section{ARTIGO ORIGINAL}

NOVAIS, Millena Pina de ${ }^{1}$, ASSUNÇÃO, Raiane Oliveira ${ }^{2}$, NASCIMENTO, Rudgero Oliveira do ${ }^{3}$

NOVAIS, Millena Pina de. ASSUNÇÃO, Raiane Oliveira. NASCIMENTO, Rudgero Oliveira do. Viabilidade de aplicação e reaproveitamento de energia solar conectada à rede elétrica para uma residência unifamiliar. Revista Científica Multidisciplinar Núcleo do Conhecimento. Ano. 06, Ed. 12, Vol. 03, pp. 185-205. Dezembro de 2021. ISSN: 2448-0959, Link de acesso: https://www.nucleodoconhecimento.com.br/engenharia-civil/viabilidade-deaplicacao

\section{RESUMO}

A busca por energia limpa e sustentável tornou-se crescente desde que a sociedade vem enfrentando diversos problemas econômicos e sociais, tais como: crise hídrica, aumentos nas contas de energia, aquecimento global, entre outros. O Brasil é um grande receptor de incidência solar, facilitando, assim, o desenvolvimento da matriz elétrica conhecida como o sistema solar fotovoltaico. Portanto, gerar e instalar energia solar apresenta-se como uma grande oportunidade ao consumidor, uma vez que seu custo-benefício chama atenção, bem como seu retorno de investimento. Neste

${ }^{1}$ Bacharelando em Engenharia Civil.

2 Bacharelando em Engenharia Civil.

3 Orientador. Especialização em Engenharia de Segurança no Trabalho. Especialização em MBA em Gerenciamento de Obras de Engenharia. Graduação em Engenharia Civil. 
contexto, o presente artigo, tem como questão norteadora: é viável, a longo prazo, gerar energia para si próprio, através do meio solar, para atender às demandas de custos e desfrutar de uma fonte sustentável, utilizando a aplicação de um sistema fotovoltaico conectado à rede de toda residência? Levando em conta todos os fatores citados, este trabalho tem como objetivo estudar a viabilidade econômica e o mecanismo que utiliza a tecnologia de geração distribuída de energia elétrica por meio de sistemas fotovoltaicos. Por meio de um estudo de caso, realizado em uma área em construção na cidade de Vitória da Conquista, no estado da Bahia, foi feita uma coleta de dados referente aos gastos de energia da residência. Na parte metodológica, foi feito um estudo da área da residência, bem como da residência em si, avaliando seus gastos mensais para futuro cálculo para viabilidade e enviando todos dados para uma empresa que forneceu informações sobre a aplicação do sistema e sobre como o sistema deveria ser aplicado. Posteriormente, com base nos dados analisados, foi realizada a aplicação da energia solar na residência e foi estabelecido aos proprietários um período para o retorno do investimento, de modo que os gastos com as contas de energia não fossem mais um problema. Desse modo, em um período de aproximadamente quatro anos, depois de quitado o valor do investimento, os gastos com energia seriam reduzidos, comprovando que é viável gerar energia para si próprio através do meio solar.

Palavras-chave: Energia Limpa e Sustentável, Sistema Fotovoltaico On-Grid, Viabilidade de Aplicação.

\section{INTRODUÇÃO}

A presente pesquisa tem por tema a viabilidade de aplicação e reaproveitamento de energia solar para a rede elétrica de uma residência unifamiliar, que se desenvolveu a partir do seguinte questionamento: é viável, a longo prazo, gerar energia para si próprio, através do meio solar, para atender às demandas de custos e desfrutar de uma fonte sustentável, utilizando a aplicação de um sistema fotovoltaico conectado à rede de toda residência? 
Sobre a temática proposta, é necessário ressaltar que é pelo fato de o país estar sujeito à altos índices de radiação solar ao longo de todo o ano que a utilização da energia fotovoltaica se torna uma opção viável para contribuir com a demanda de energia requerida pela população. A produção de energia, juntamente ao consumidor final, pode alegar economias para o setor, reduzindo gastos de transmissão e distribuição da energia elétrica.

Um grande trecho do território brasileiro está localizado próximo à linha do Equador, gerando uma enorme quantidade de radiação solar que é compartilhada por todo o território, tornando o país em um dos locais mais favoráveis para a utilização da energia solar (PESSOA, 2011).

No Brasil, a população vem mostrando cada vez mais interesse no tema da sustentabilidade e, de acordo com os estudos da ANEEL (Agência Nacional de Energia Elétrica), tem buscado por opções de energia renovável para serem utilizadas dentro de suas próprias casas, como, por exemplo: energia solar (por meio da aplicação de placas solares) energia eólica e recursos hídricos.

Segundo o Manual de Engenharia Fotovoltaicos (2014), a energia solar é utilizada por meio de um sistema isolado, por meio de um sistema conectado à rede ou pela junção desses dois sistemas, que gera um sistema híbrido.

Os raios solares são recebidos e absorvidos pelas placas e revertidos, através de inversores ou baterias (depende do tipo de sistemas que for escolhido), fazendo com que a irradiação solar obtida se converta em energia elétrica por meio de equipamentos semicondutores, ou seja, dos painéis solares. Esses painéis solares, por sua vez, são conectados a inversores, que transformam a corrente alterada em corrente contínua a ser distribuída por toda rede elétrica residencial, comercial, entre outros pontos.

A energia solar, por sua vez, é uma fonte renovável geradora de energia que apresenta inúmeras vantagens. Apesar de seu custo elevado e das peculiaridades existentes em sua aplicação, atualmente, ela vem sendo muito procurada por aqueles 
que buscam tentar reduzir os custos com energia ou que desejam, de alguma forma, tentar amenizar os impactos no meio ambiente.

O objetivo principal da pesquisa foi estudar a viabilidade econômica e o mecanismo que utiliza a tecnologia de geração distribuída de energia elétrica por meio de sistemas fotovoltaicos, por meio de um estudo de caso, realizado em uma área em construção na cidade de Vitória da Conquista, no estado da Bahia. Nesse estudo, retrata-se um modelo de uma residência que possui energia sustentável, com o propósito de apresentar intervenções que são favoráveis tanto para o consumidor final quanto para o meio ambiente. Com base nisso, os objetivos específicos foram:

- Fazer uma apresentação sobre a energia fotovoltaica, bem como seus métodos, vantagens e desvantagens;

- Apresentar a residência e seu local para futura instalação do sistema fotovoltaico conectado à rede elétrica;

- Identificar o sistema que será implantado na residência, bem como seu retorno em longo prazo.

O estudo e a compreensão do tema se fazem necessários, tendo em vista que o aumento das contas de luz causa preocupação na população em geral. Muitos estão em busca de recursos que possam ajudar no controle dos gastos, que, em vista do atual cenário mundial, tem aumentado e se tornado preocupante. Por conta do custo, pouco se é pensado em relação a aplicação de energia solar em residências unifamiliares, porém, na tentativa de ajudar os moradores dessas residências, pensou-se nesse estudo de visibilidade e aplicação dessa fonte renovável, uma vez que, a longo prazo, é possível lucrar com essa alternativa, de modo que todos os gastos tidos com sua aplicação recompensem no final. Esse sistema de produção de energia pode atender a demanda de toda uma residência, trazendo melhorias para o consumidor e para o meio ambiente.

Segundo apuração de dados da Associação Brasileira de Energia Solar Fotovoltaica (ABSOLAR, 2018), 89\% dos brasileiros desejam possuir um sistema de energia 
renovável em suas casas, uma vez que ela: gera renda ao país, diminui os impactos socioambientais e reduz os custos com energia, fatos favoráveis tanto para consumidores quanto para produtores.

A escolha do tema é referente a um futuro sustentável e inovador, uma vez que a aplicação de energia solar é vista como um importante passo para o desenvolvimento de um mundo mais sustentável. O Brasil é um grande receptor de energia solar e deveria fazer um bom proveito dessa característica para a implementação de um sistema de energia limpa.

Segundo a NeoSolar (2018), empresa especializada na produção de energia solar, localizada na cidade de São Paulo, levando em conta a economia e uma retribuição de aproximadamente $25 \%$ ao ano do valor aplicado, a utilização do sistema gera uma valorização de $10 \%$ do valor do imóvel logo após a instalação. Uma pesquisa publicada pelo jornal New York Times, apontou que o sistema valoriza o imóvel, aumentando cerca de quatro dólares por Watt instalado.

\section{FUNDAMENTAÇÃO TEÓRICA}

\subsection{PRODUÇÃO ENERGÉTICA NO MUNDO}

É notório que, diante do aumento das contas de energia, da emissão de gases poluentes e da busca por uma fonte renovável de energia, a energia solar vem sendo um ponto importante para todo o mundo. A busca por esse meio renovável acaba causando um crescente aumento no investimento dos sistemas fotovoltaicos (MILIANO; SILVA, 2018)

Tabela 1 - Países que mais investiram em energia solar fotovoltaica em 2018.

\begin{tabular}{|l|l|l|}
\hline $\mathbf{1}^{\circ}$ & China & $\mathbf{4 5 , 0} \mathbf{G W}$ \\
\hline $\mathbf{2}^{\mathbf{0}}$ & Índia & $10,8 \mathrm{GW}$ \\
\hline 3ㅇ $^{-}$ & USA & $10,6 \mathrm{GW}$ \\
\hline 4 $^{-}$ & Japão & $6,5 \mathrm{GW}$ \\
\hline
\end{tabular}




\begin{tabular}{|l|l|l|}
\hline $\mathbf{5}^{\mathbf{0}}$ & Austrália & $3,8 \mathrm{GW}$ \\
\hline $\mathbf{6}^{\mathbf{0}}$ & Alemanha & $3,0 \mathrm{GW}$ \\
\hline $\mathbf{7}^{\mathbf{0}}$ & México & $2,7 \mathrm{GW}$ \\
\hline $\mathbf{8}^{\mathbf{0}}$ & Coreia do Sul & $2,0 \mathrm{GW}$ \\
\hline $\mathbf{9}^{-}$ & Turquia & $1,6 \mathrm{GW}$ \\
\hline $\mathbf{1 0}^{-}$ & Holanda & $1,3 \mathrm{GW}$ \\
\hline
\end{tabular}

Fonte: Adaptado de Snapshot of Global PV Markets, IEA PVPS, 2019.

Como mostrado na Tabela 1, no ano de 2019, a China se destacou como maior país investidor dessa fonte renovável, já a Índia, com uma diferença de 34,2 GW, se destacou como o segundo país que mais investe nessa energia.

\subsection{PRODUÇÃO ENERGÉTICA NO BRASIL}

Como apresentado na abaixo, figura 1, o Brasil dispõe de várias matrizes elétricas e, dentre elas, se destacam as matrizes hídrica, eólica, biomassa, gás natural e petróleo. A produção de energia solar fotovoltaica centralizada ainda ocupa $1,3 \%$ da matriz elétrica, com 1,268 MW de potência acumulada. 
Figura 1 - Matriz elétrica brasileira em 2009.

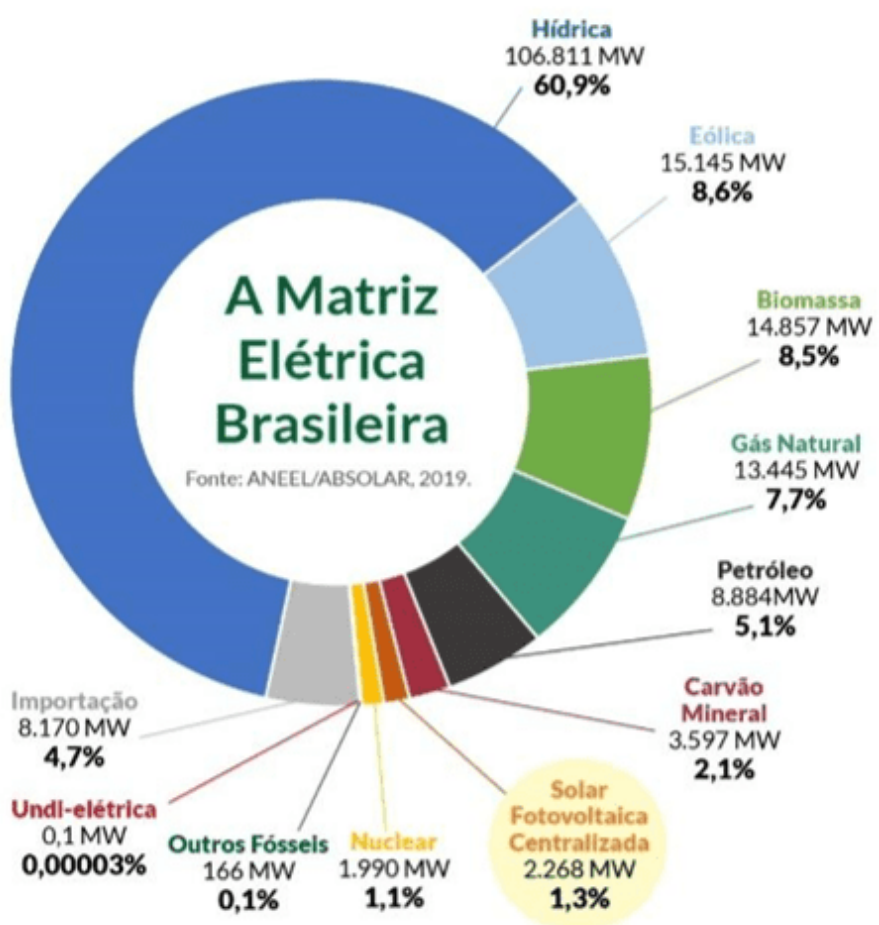

Fonte: Absolar, 2019.

Segundo a ABSOLAR, o país possui, atualmente, 93.597 sistemas solares fotovoltaicos conectados à rede, que representam mais de $R \$ 5,6$ bilhões em investimentos acumulados. Atingindo uma marca histórica de 1 gigawatt (GW) de potência instalada e distribuída por solar fotovoltaica em residências, comércios, indústrias, produtores rurais, prédios públicos e pequenos terrenos (PORTAL SOLAR, 2019). 
Figura 2 - Geração distribuída solar fotovoltaica no Brasil por classe de consumo.

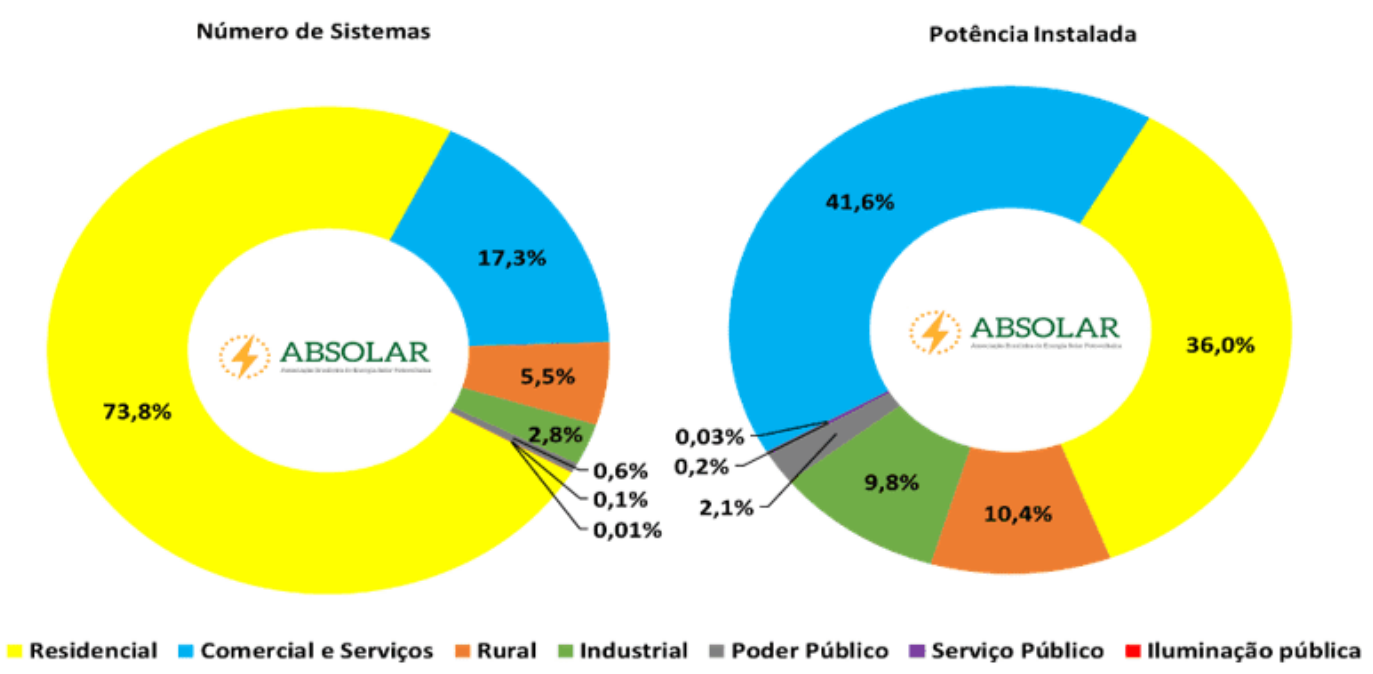

Fonte: Portal Solar, 2019.

$\mathrm{Na}$ figura 2, temos destaque para os consumidores residenciais $(73,8 \%$ de sistemas instalados), seguido pelo setor comercial e serviços $(17,3 \%)$, rural $(5,5 \%)$, industrial $(2,8 \%)$, poder público $(0.6 \%)$, serviço público $(0,1 \%)$ e iluminação pública $(0,01 \%)$.

O Brasil se destaca como um dos países mais favoráveis para a produção de energia solar, por conta de sua localização, que permite altos níveis de irradiação solar, o tornando ainda mais favorável que os países que mais investem nessa fonte de energia. Na figura 3, destaca-se o estado de Minas Gerais como um grande produtor da energia solar no país, com 196,7 GW de potência instalada. 
Figura 3 - Ranking estadual de geração distribuída solar fotovoltaica.

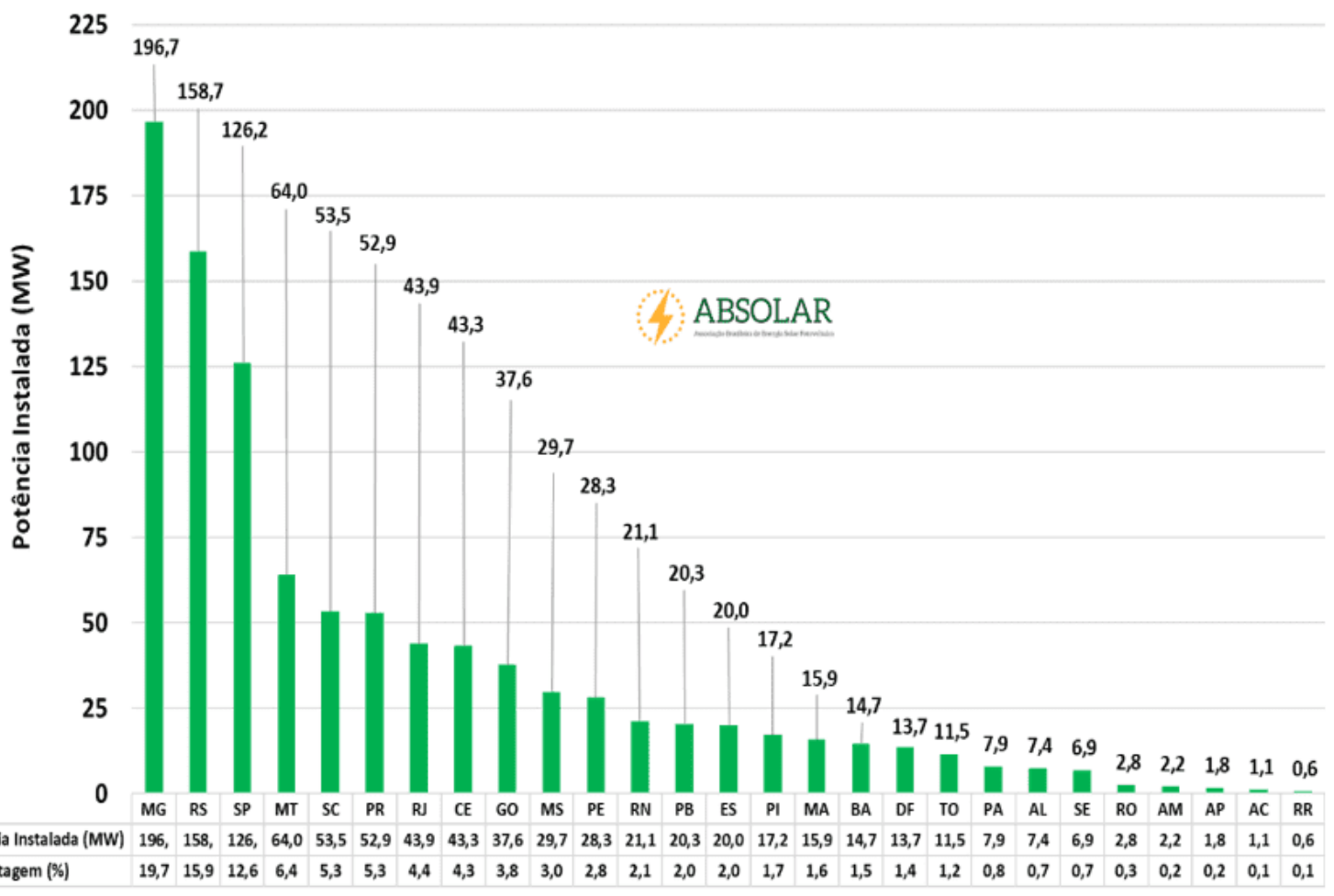

Fonte: Portal Solar, 2019.

\subsection{INCIDÊNCIA SOLAR NO BRASIL E NO NORDESTE}

Segundo o Atlas Brasileiro de Energia Solar, em 2006, a radiação solar que incide diariamente no Brasil está entre 4500 a $6300 \mathrm{Wh} / \mathrm{m}^{2}$, apresentando condições mais que favoráveis para o desenvolvimento da energia solar, uma vez que o país já se destaca por ter uma das matrizes energéticas mais limpa do mundo. (SÁ, 2016)

Disponível em: https://www.nucleodoconhecimento.com.br/engenharia-civil/viabilidade-deaplicacao 
Figura 4 - Radiação solar no Brasil.

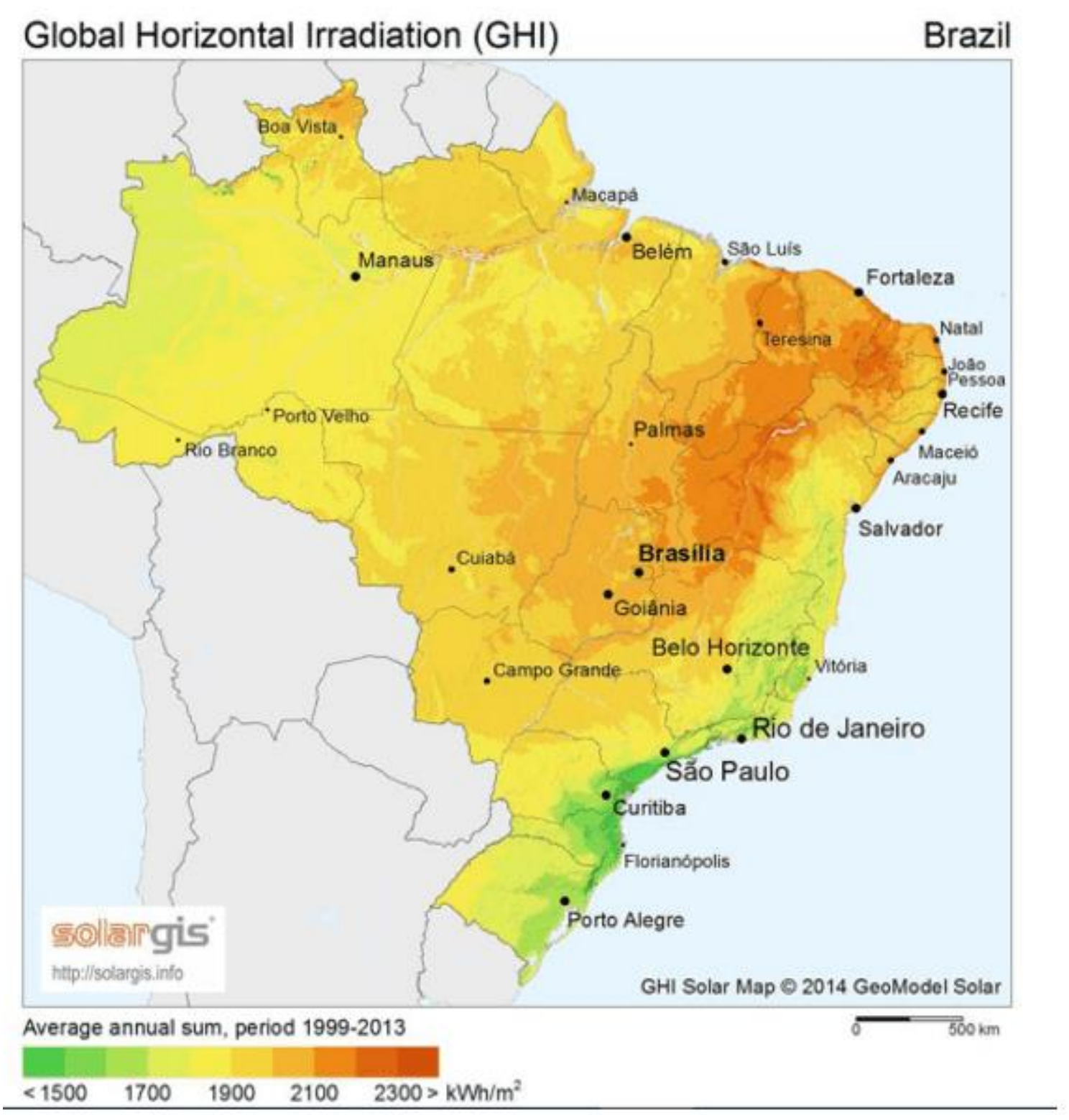

Fonte: SolarGIS, 2015.

De acordo com a figura 4, pode-se observar as áreas do Brasil que que mais recebem radiação solar, e, dentre estas regiões, dá-se uma maior importância à região Nordeste, que é a região que mais se destaca quanto ao recebimento de radiação solar, porém, que ainda não se apresenta entre as que mais investem nessa produção de energia limpa.

Disponível em: https://www.nucleodoconhecimento.com.br/engenharia-civil/viabilidade-deaplicacao 
Figura 5 - Mapa das regiões com média global de radiação solar.

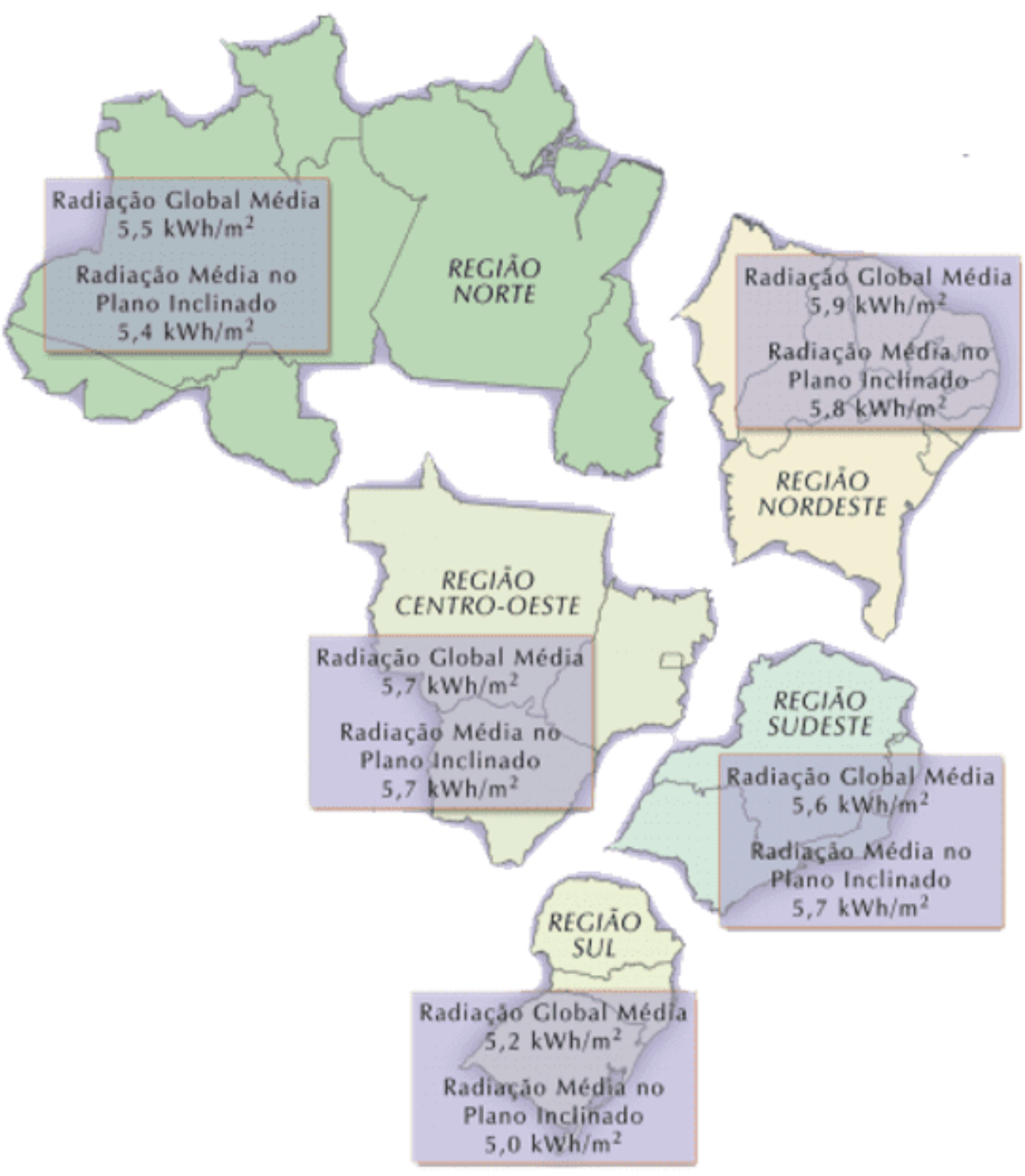

Fonte: Icentive Solar, 2018.

A figura 5 apresenta os diferentes níveis de radiação solar no país, destacando a região nordeste com uma radiação média global de $5,9 \mathrm{kwh} / \mathrm{m}^{2}$, seguida pela região centro-oeste, com a média de $5,7 \mathrm{kwh} / \mathrm{m}^{2}$, e, por último, a área como menos incidência, a região sul, com $5,2 \mathrm{kwh} / \mathrm{m}^{2}$. Em uma análise completa do mapa, é notável que a diferença entre os índices globais de radiação solar no país é baixa, realçando ainda mais a grande carga de incidência solar existente no país.

Disponível em: https://www.nucleodoconhecimento.com.br/engenharia-civil/viabilidade-deaplicacao 


\subsection{SISTEMAS FOTOVOLTAICOS}

Em 2020, no Brasil, houve um aumento na aplicação de fontes renováveis, em que se registrou a instalação de 7 GW (gigawatt) de potência instalada de energia solar. Por conta da maior procura por essa fonte renovável, se esperava que houvesse um aumento de $100 \%$ na aplicação de placas solares, uma vez que o aumento gradativo no custo da energia causou preocupação aos consumidores (MENDES; SANTOS, 2019)

A respeito da energia solar, vale destacar as placas condutoras de calor (utilizadas no aquecimento de água) e as geradoras de energia elétrica fotovoltaicas (que se conectam à rede elétrica), subdivididas em on-grid e off-grid (MENDES; SANTOS, 2019). O sistema de energia solar fotovoltaica utiliza painéis solares que absorvem a luz e geram, pelo efeito fotovoltaico, correntes elétricas alternadas, que são convertidas para correntes contínuas pelo inversor solar. Desse modo, a eletricidade está pronta para ser distribuída no local, gerar créditos de energia ou ser armazenada (CRESESB, 2014).

O sistema on-grid, ou sistema fotovoltaico conectado à rede, como é mais comumente chamado, é aquele que transforma a energia do sol, recebido pelas placas solares, por meio de inversores elétricos, convertendo a corrente da energia contínua, de modo que ela possa ser direcionada diretamente para a rede elétrica da residência (STROM BRASIL).

Os sistemas fotovoltaicos possuem as seguintes vantagens:

- É uma opção mais barata, pois não necessita de baterias para o armazenamento da energia produzida;

- É um sistema silencioso;

- Apresenta baixo custo de manutenção, pois as placas têm vida útil de 25 a 30 anos; 
- Caso o proprietário possua outra residência ou empreendimento sob o mesmo CPF ou CNPJ, ele pode utilizar os créditos para abater a conta de energia desses locais (HECK, 2018).

A distribuição do sistema on-grid ocorre quando a incidência solar é captada, em forma de corrente contínua, pelos painéis solares instalados no telhado da residência, que é posteriormente jogado para um inversor, que torna a energia produzida em corrente alternada, sendo associada à energia fornecida pelas redes elétricas e estando pronta para a utilização de toda residência. (BLUESOL, 2019)

Figura 6 - Sistema on-grid.

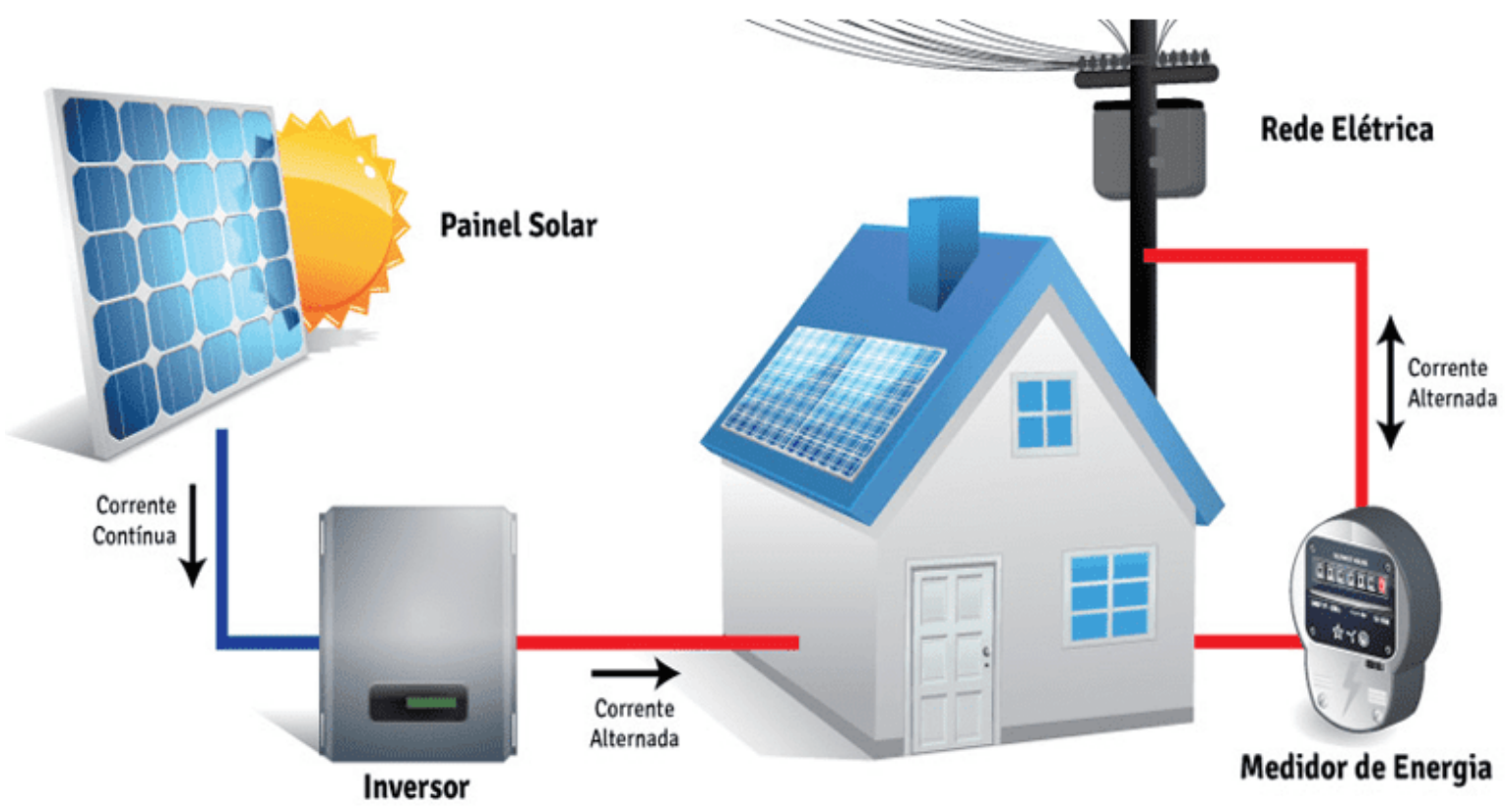

Fonte: Roma Engenharia de Energia, 2018.

Como já citado, o sistema on-grid apresenta um modo vantajoso de uso e instalação, além de conseguir gerar mais energia do que é propriamente utilizada, uma vez que converte e distribui uma grande quantidade de energia em curto prazo. O sistema offgrid, por sua vez, é formado por sistemas isolados ou autônomos, que são construídos para um propósito específico, não conectado à toda rede elétrica. Ele funciona por meio de baterias, armazenando a energia para ser utilizada em um momento específico (STROM BRASIL, 2014).

Disponível em: https://www.nucleodoconhecimento.com.br/engenharia-civil/viabilidade-deaplicacao 
Para sua funcionalidade e distribuição, o sistema off-grid, ao contrário do on-grid, não precisa se associar à energia que é fornecida pela rede elétrica, para isso, ele dispõe de baterias, que permitem o seu funcionamento adequado, de forma a atender sua demanda. Sua distribuição é bem semelhante ao outro sistema, porém, além de não precisar se associar a rede elétrica para ser distribuído pela residência, a energia produzida excesso não é enviada para a rede elétrica, e sim armazenada nas baterias (BLUESOL, 2019).

Figura 7 - Sistema off-grid.

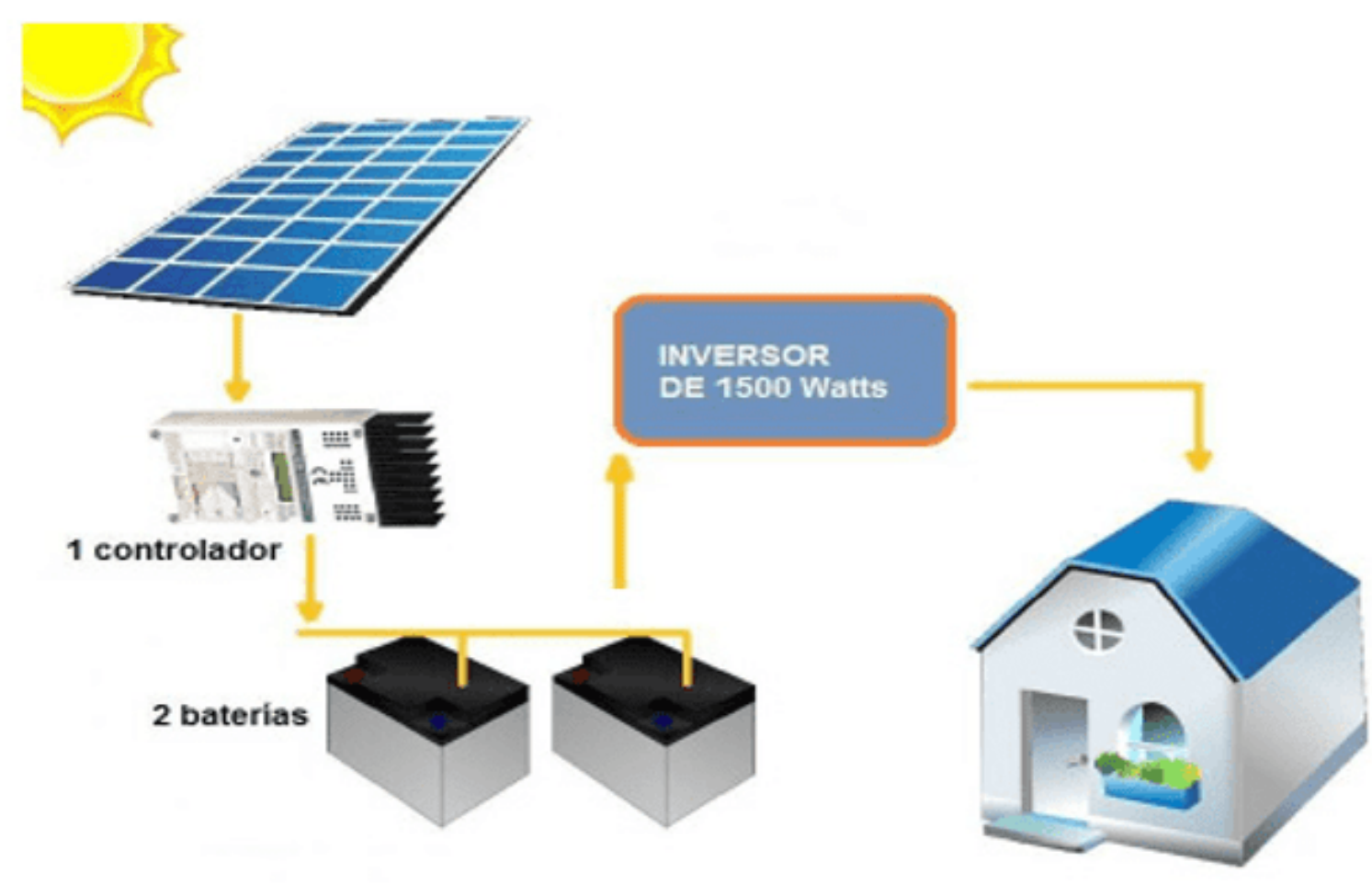

Fonte: Roma Engenharia de Energia, 2018.

A aplicação de qualquer um dos sistemas fotovoltaicos apresenta como vantagem a produção de energia limpa, causando um impacto favorável em todo o país e no meio ambiente, além do favorecimento próprio, pois, com o investimento em geração de energia própria, a longo prazo, há a diminuição dos custos com energia. 


\section{PROCEDIMENTOS METODOLÓGICOS}

\subsection{ESTUDO DE CASO}

\subsection{1 ÁREA E LOCALIZAÇÃO DE ESTUDO}

A área de estudo está localizada na cidade de Vitória da Conquista, de coordenadas geográficas: 14.865833 de latitude Sul e 40.838889 de longitude Oeste. Com uma altitude média de 923 m, com clima tropical de altitude (BARRETO; VIEGA, 2019).

Tabela 2 - Níveis de radiação solar na cidade de Vitória da Conquista.

\begin{tabular}{|l|l|}
\hline DATA & RADIAÇÃO SOLAR $\left(\mathbf{W} / \mathbf{m}^{\mathbf{2}}\right)$ \\
\hline $\mathbf{2 6} / \mathbf{1 0} / \mathbf{2 0 2 1}$ & $6269 \mathrm{w} / \mathrm{m}^{2}$ \\
\hline $\mathbf{2 7 / 1 0} / \mathbf{2 0 2 1}$ & $5917 \mathrm{w} / \mathrm{m}^{2}$ \\
\hline $\mathbf{2 8 / 1 0 / 2 0 2 1}$ & $6061 \mathrm{w} / \mathrm{m}^{2}$ \\
\hline $\mathbf{2 9} / \mathbf{1 0} / \mathbf{2 0 2 1}$ & $7215 \mathrm{w} / \mathrm{m}^{2}$ \\
\hline $\mathbf{3 0 / 1 0 / 2 0 2 1}$ & $6931 \mathrm{w} / \mathrm{m}^{2}$ \\
\hline $\mathbf{3 1 / 1 0 / 2 0 2 1}$ & $4677 \mathrm{w} / \mathrm{m}^{2}$ \\
\hline $\mathbf{0 1 / 1 1 / 2 0 2 1}$ & $2101 \mathrm{w} / \mathrm{m}^{2}$ \\
\hline $\mathbf{0 2} / \mathbf{1 1} / \mathbf{2 0 2 1}$ & $3304 \mathrm{w} / \mathrm{m}^{2}$ \\
\hline $\mathbf{0 3 / 1 1 / 2 0 2 1}$ & $2117 \mathrm{w} / \mathrm{m}^{2}$ \\
\hline $\mathbf{0 4 / 1 1 / 2 0 2 1}$ & $2286 \mathrm{w} / \mathrm{m}^{2}$ \\
\hline
\end{tabular}

Fonte: TuTiempo.net, 2021, adaptado pelos autores.

De acordo com a Tabela 2, a cidade de Vitória da Conquista apresentava altos níveis de incidência solar, mas a partir do dia 01 de novembro os níveis começaram a mostrar uma queda, causada pelo clima da cidade, que se encontrava em uma estação chuvosa, apresentando uma média de 4687,8 w/m², tirado em dez dias.

A casa alvo do projeto se encontra no bairro Ibirapuera, na Travessa Feira de Santana, número 66. Uma casa de tamanho padrão, com um terreno de $250 \mathrm{~m}^{2}$, que se encontra 
em uma área com casas vizinhas, o que não interfere tanto na captação da luz solar. Com latitude de -14.945530 e longitude de -40.960999 , conforme apresentado na legenda na figura.

Figura 8 -Localização do terreno (apresentado em amarelo).

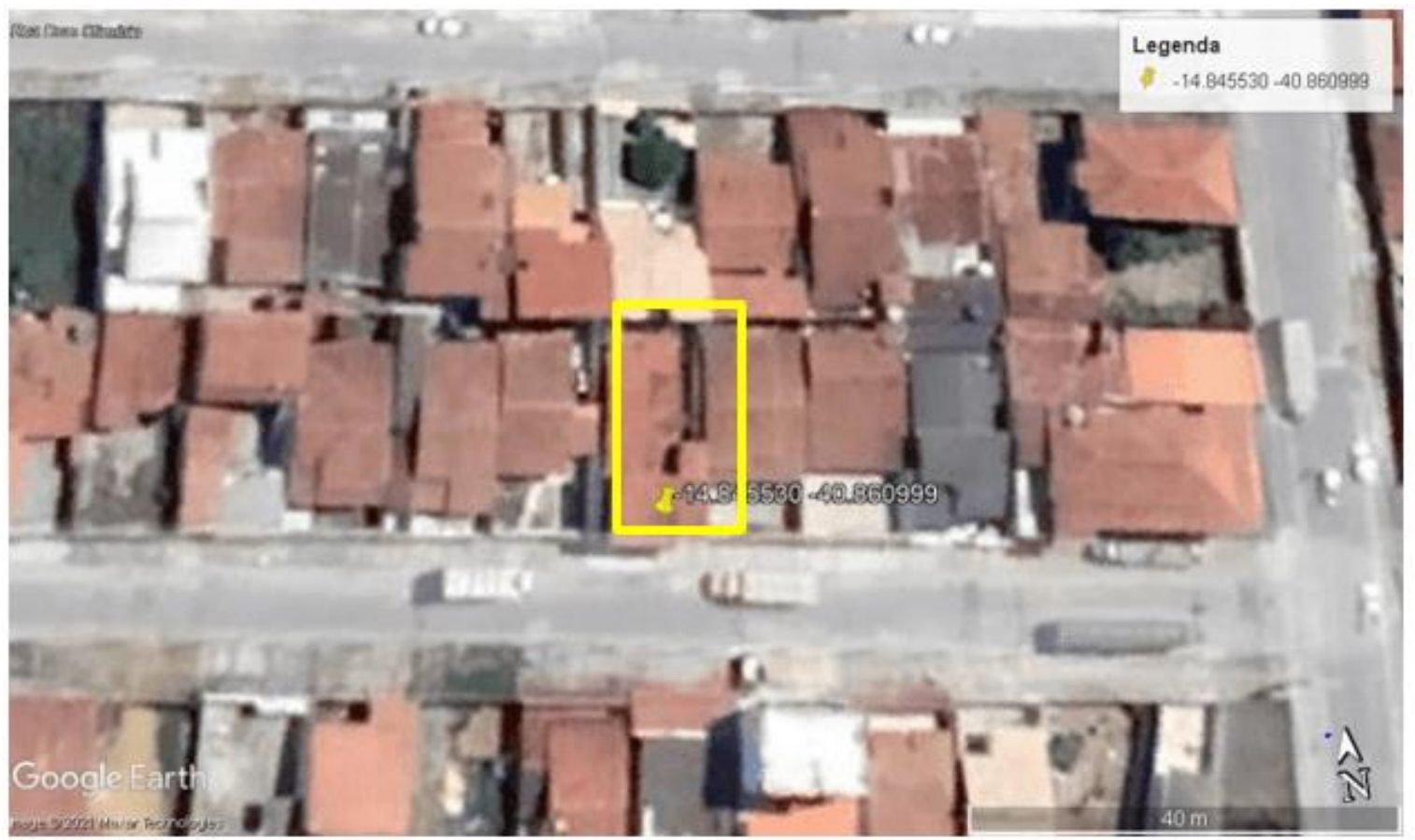

Fonte: Google Earth Pro, 2021.

\subsubsection{PROJETO DE ESTUDO}

Trata-se de uma residência com 3 (três) dormitórios, 1 (um) banheiro, 1 (uma) cozinha, 2 (duas) salas e 1 (uma) área de serviço. Composta por 3 moradores, em média, como é comum entre as casas da região. 
Figura 9 - Imagem frontal da residência.

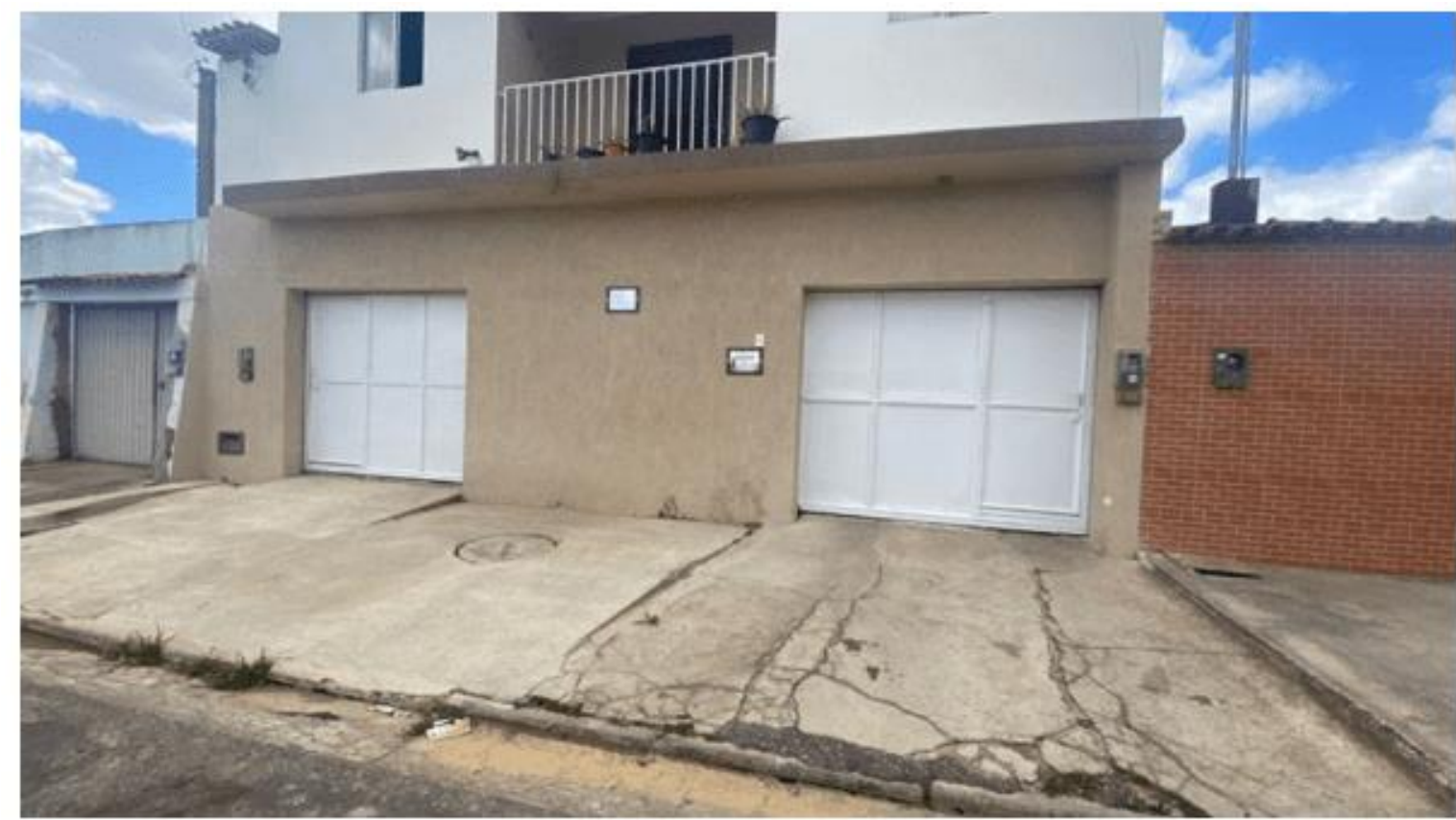

Fonte: Os autores.

A residência contém eletrodomésticos como geladeira, fogão, máquina de lavar e TV, que apresentam uma grande eficiência energética, conforme apresentado em seus selos de eficiência da PROCEL (Programa Nacional de Conservação de Energia Elétrica).

No período em que a pesquisa foi realizada, a residência recebia energia por meio da rede elétrica pública, pelo valor médio mensal de $R \$ 192,2$, conforme a média dos gastos apresentada na Tabela 3.

Tabela 3 - Gasto mensal da residência em 8 meses.

\begin{tabular}{|l|l|l|}
\hline DATA & CUSTO MENSAL (R\$) & CONSUMO MENSAL (KW/h) \\
\hline $\mathbf{2 6 / 1 1 / 2 0 2 0}$ & $R \$ 139,48$ & $158 \mathrm{KW} / \mathrm{h}$ \\
\hline $\mathbf{2 9 / 1 2 / 2 0 2 0}$ & $\mathrm{R} \$ 166,07$ & $167 \mathrm{KW} / \mathrm{h}$ \\
\hline $\mathbf{2 9 / 0 3 / 2 0 2 1}$ & $\mathrm{R} \$ 164,99$ & $184 \mathrm{KW} / \mathrm{h}$ \\
\hline $\mathbf{3 0 / 0 4 / 2 0 2 1}$ & $\mathrm{R} \$ 169,48$ & $189 \mathrm{KW} / \mathrm{h}$ \\
\hline
\end{tabular}




\begin{tabular}{|l|l|l|}
\hline $\mathbf{0 7 / 0 7 / 2 0 2 1}$ & $\mathrm{R} \$ 230,79$ & $221 \mathrm{KW} / \mathrm{h}$ \\
\hline $\mathbf{0 5 / 0 8 / 2 0 2 1}$ & $\mathrm{R} \$ 247,73$ & $182 \mathrm{KW} / \mathrm{h}$ \\
\hline $\mathbf{2 7 / 0 8 / 2 0 2 1}$ & $\mathrm{R} \$ 200,43$ & $185 \mathrm{KW} / \mathrm{h}$ \\
\hline $\mathbf{2 8 / 1 0 / 2 0 2 1}$ & $\mathrm{R} \$ 218,63$ & $182 \mathrm{KW} / \mathrm{h}$ \\
\hline
\end{tabular}

Fonte: Os autores

\subsubsection{LEVANTAMENTO DE DADOS E O SISTEMA PARA APLICAÇÃO NA RESIDÊNCIA}

Para trazer os dados à atualidade e os adaptar para a implantação na residência de estudo, foi realizada uma busca por empresas do ramo de energia solar que realizassem uma cotação inicial e uma análise do consumidor para tomada de decisão final.

A empresa "ILUMISOL Energia Solar", que possui uma unidade localizada na própria cidade de Vitória da Conquista, forneceu um orçamento para a instalação do sistema com base última conta de energia, com valores e consumo mensal, com a qual é feita uma análise do consumo atual da rede elétrica da residência. Também foram coletados dados de irradiação solar.

Tabela 4 - Níveis de irradiação solar.

\begin{tabular}{|l|l|}
\hline MÊS & IRRADIAÇÃO GLOBAL \\
\hline JANEIRO & $6.106 \mathrm{kWh} / \mathrm{m}^{2} /$ dia \\
\hline FEVEREIRO & $6.162 \mathrm{kWh} / \mathrm{m}^{2} /$ dia \\
\hline ABRIL & $5.476 \mathrm{kWh} / \mathrm{m}^{2} /$ dia \\
\hline MARÇO & $4.968 \mathrm{kWh} / \mathrm{m}^{2} /$ dia \\
\hline MAIO & $4.613 \mathrm{kWh} / \mathrm{m}^{2} /$ dia \\
\hline JUNHO & $3.641 \mathrm{kWh} / \mathrm{m}^{2} /$ dia \\
\hline JULHO & $3.83 \mathrm{kWh} / \mathrm{m}^{2} /$ dia \\
\hline AGOSTO & $4.677 \mathrm{kWh} / \mathrm{m}^{2} /$ dia \\
\hline
\end{tabular}




\begin{tabular}{|l|l|}
\hline SETEMBRO & $5.45 \mathrm{kWh} / \mathrm{m}^{2} / \mathrm{dia}$ \\
\hline OUTUBRO & $5.986 \mathrm{kWh} / \mathrm{m}^{2} / \mathrm{dia}$ \\
\hline NOVEMBRO & $6.043 \mathrm{kWh} / \mathrm{m}^{2} / \mathrm{dia}$ \\
\hline DEZEMBRO & $5.438 \mathrm{kWh} / \mathrm{m}^{2} / \mathrm{dia}$ \\
\hline
\end{tabular}

Fonte: Adaptado de llumisol Energia Solar, 2021.

De acordo com dados da análise realizada para tal residência, o sistema que se apresentou como a melhor opção foi o sistema on-grid, que é conectado à rede elétrica, composto por painéis fotovoltaicos, inversor grid tie e fixadores das para o telhado, ocupando uma área de $12,12 \mathrm{~m}^{2}$ e podendo ser dividido pelas duas águas, como meio de distribuição de carga.

Figura 10 - Sistema on-grid e seus equipamentos.

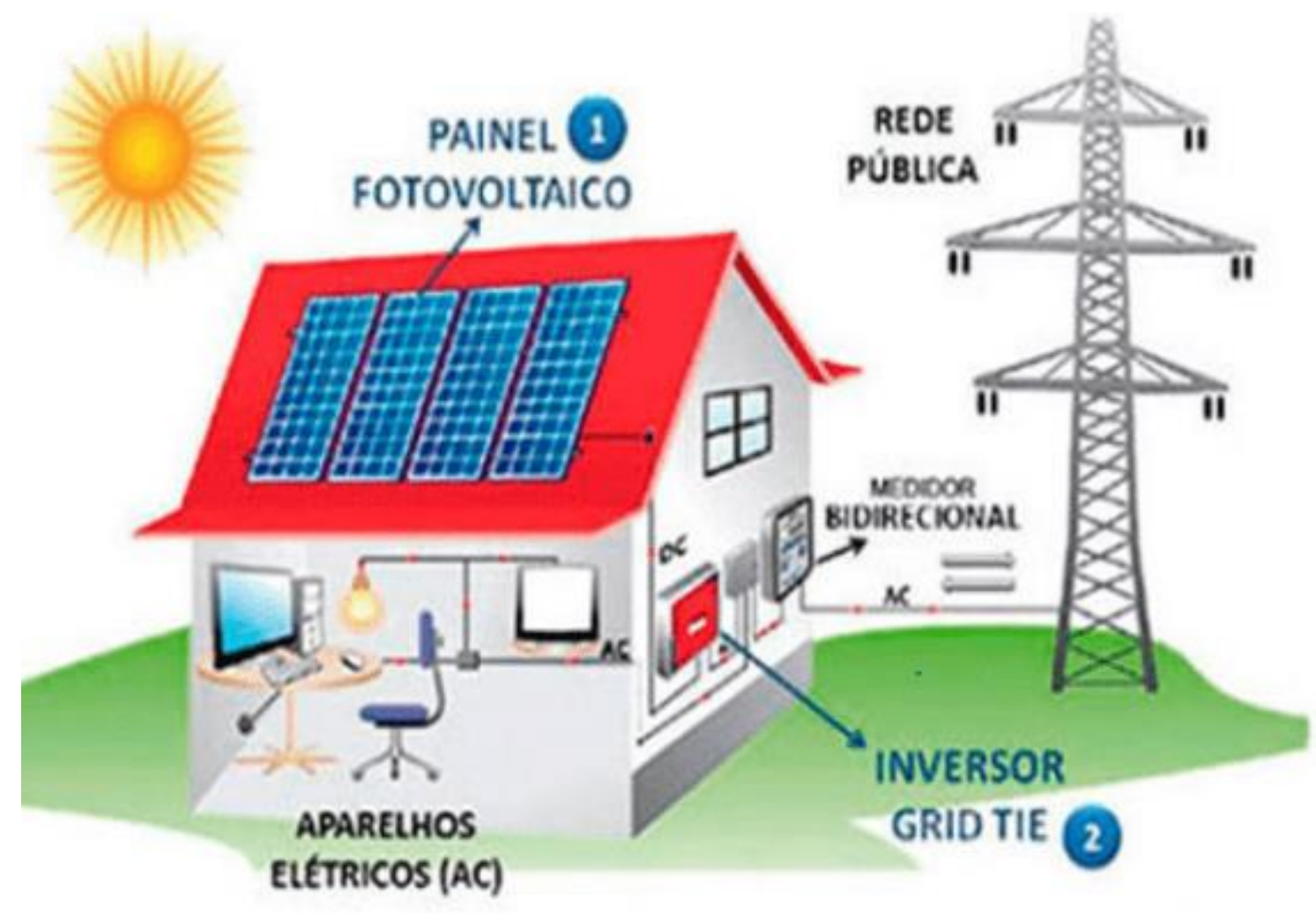

Fonte: Ilumisol Energia Solar, 2021.

Disponível em: https://www.nucleodoconhecimento.com.br/engenharia-civil/viabilidade-deaplicacao 


\section{ANÁLISE DOS RESULTADOS}

Após coleta de dados fornecido pela empresa llumisol, foi constatado que seria necessário 1 (um) sistema fotovoltaico conectado à rede elétrica com uma potência de $2.43 \mathrm{kWp}$, que seria capaz de suprir o consumo anual de energia elétrica, produzindo, aproximadamente $3.439 \mathrm{kWp}$ ao ano. O sistema em questão se tratava de um sistema de classe monofásico, que teve suas placas posicionadas no sentido leste-oeste da cidade de Vitória da Conquista.

Analisando o consumo de acordo o gasto da residência, obteve-se um consumo médio anual de $2.139 \mathrm{KWh}$ (estimado em $\mathrm{R} \$ 1.925,10$ ) e um consumo médio mensal de 178 KWh (estimado em R $\$ 160,43$ ).

Figura 11 - Gráfico de consumo atual da rede elétrica da residência.

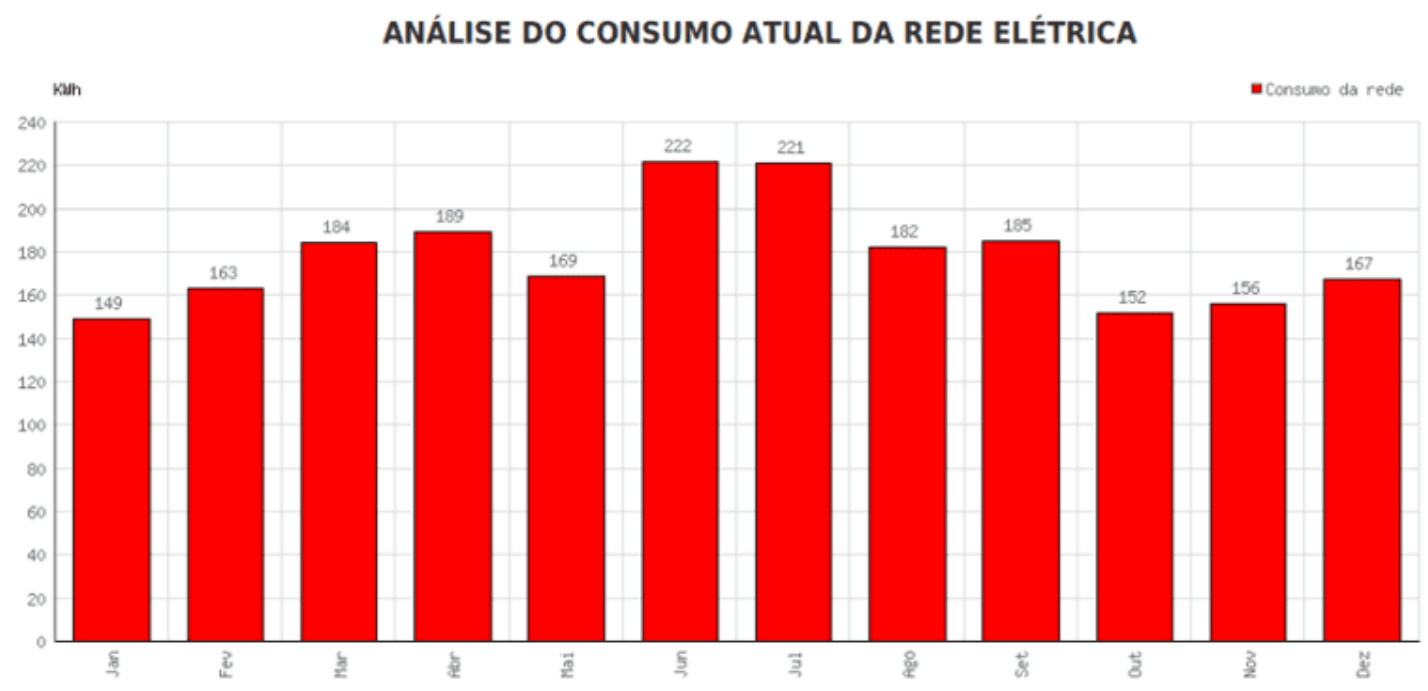

Fonte: Ilumisol Energia Solar, 2021.

Com base no sistema proposto para implantação na residência, desenvolveu-se um sistema composto por 6 (seis) módulos fotovoltaicos de 405W cada, considerando todos os fatores de interferência na localidade (temperatura, inclinação, irradiação solar). Composto também por 1 (um) inversor solar 3KTLM-G2, cabos, conectores e equipamentos para instalação. Foi calculado um investimento necessário de $R \$$ 
16.298,45 (dezesseis mil, duzentos e noventa e oito reais e quarenta e cinco centavos), que poderiam ser desembolsados por meio de parcelamentos e financiamentos bancários.

A empresa apresentou uma análise financeira para os próximos 25 anos, com geração da capacidade de $83 \%$. Com uma geração média mensal do sistema de $287 \mathrm{kWh}$, aplicando um custo médio de 0,90 reais a cada $1 \mathrm{kWh}$. Na tabela 5, apresenta-se, na segunda coluna, a geração de energia acumulada; na terceira coluna, a economia gerada por ano e na quarta coluna, a economia acumulada para fornecer o retorno do investimento em reais.

Tabela 5 - Análise financeira para 25 anos.

\begin{tabular}{|c|c|c|c|}
\hline ANO & $\begin{array}{l}\text { Geração de energia } \\
\text { acumulada }(\mathrm{kWh})\end{array}$ & $\begin{array}{l}\text { Economia } \\
\text { gerada/ano - R\$ }\end{array}$ & $\begin{array}{l}\text { Economia acumulada pelo } \\
\text { retorno do investimento }(R \$)\end{array}$ \\
\hline $1 \stackrel{0}{0}$ & 3.415 & $3.380,78$ & $3.380,78$ \\
\hline $2^{\circ}$ & 6.806 & $3.692,82$ & $7.073,60$ \\
\hline $3^{\circ}$ & 10.173 & $4.033,67$ & $11.107,27$ \\
\hline $4^{\circ}$ & 13.517 & $4.405,98$ & $15.513,25$ \\
\hline $5^{0}$ & 16.837 & $4.812,65$ & $20.325,90$ \\
\hline $6^{\circ}$ & 20.134 & $5.256,86$ & $25.582,76$ \\
\hline $7^{0}$ & 23.408 & $5.742,07$ & $31.324,83$ \\
\hline $8^{\circ}$ & 26.659 & $6.272,06$ & $37.596,89$ \\
\hline $9^{\circ}$ & 29.888 & $6.850,97$ & $44.447,86$ \\
\hline $10^{\circ}$ & 33.093 & $7.483,31$ & $51.931,17$ \\
\hline $11^{\circ}$ & 36.277 & $8.174,02$ & $60.105,20$ \\
\hline $12^{\circ}$ & 39.438 & $8.928,49$ & $69.033,68$ \\
\hline $13^{0}$ & 42.577 & $9.752,59$ & $78.786,27$ \\
\hline $14^{\circ}$ & 45.693 & $10.652,75$ & $89.439,02$ \\
\hline $15^{\circ}$ & 48.788 & $11.636,00$ & $101.075,02$ \\
\hline $16^{\circ}$ & 51.862 & $12.710,00$ & $113.785,02$ \\
\hline
\end{tabular}




\begin{tabular}{|l|l|l|l|}
\hline $17^{\circ}$ & 54.914 & $13.883,14$ & $127.668,16$ \\
\hline $18^{\circ}$ & 57.944 & $15.164,55$ & $142.832,71$ \\
\hline $19^{\circ}$ & 60.954 & $16.564,24$ & $159.396,94$ \\
\hline $20^{\circ}$ & 63.942 & $18.093,12$ & $177.490,06$ \\
\hline $21^{\circ}$ & 66.909 & $19.763,11$ & $197.253,17$ \\
\hline $22^{\circ}$ & 69.856 & $21.587,25$ & $218.840,41$ \\
\hline $23^{\circ}$ & 72.782 & $23.579,75$ & $242.420,16$ \\
\hline $24^{\circ}$ & 75.687 & $25.756,16$ & $268.176,32$ \\
\hline $25^{\circ}$ & 78.572 & $28.133,45$ & $296.309,77$ \\
\hline
\end{tabular}

Fonte: Adaptado de llumisol Energia Solar, 2021.

Conforme a análise realizada pela empresa, o consumidor teria 25 anos garantidos de geração de energia, gerando uma economia de 280.011,32 nestes anos, e o retorno do investimento se apresentaria em aproximadamente 4 anos.

Também é válido ressaltar que, perante todo o valor alto de investimento, o retorno que a energia solar oferece pela sua aplicação é mais que viável, uma vez que, por ser uma energia limpa, traz benefícios tanto aos moradores da residência como ao meio ambiente, ajudando no aumento da exploração dessa fonte energética.

\section{CONSIDERAÇÕES FINAIS}

Por meio do estudo de caso desenvolvido, é possível afirmar que a implantação do sistema fotovoltaico on-grid se destaca como viável pelo seu custo-benefício (redução de gasto mensal) e por ser meio de produção de energia limpa. Para a residência estudada, calculou-se um período de 4 anos para a quitação dos equipamentos e o começo do retorno do investimento. Os consumidores foram certificados que as variações no valor da energia se estabilizariam e retornariam para como costumavam ser, dando liberdade aos consumidores de utilizar suas economias para outros fins lucrativos. 
O sistema fotovoltaico causa melhoras na qualidade de vida, no meio ambiente e na eficiência energética. Com base nisso, se mostra necessário um aumento da matriz energética de energia solar fotovoltaica, para que se desperte o interesse de outros consumidores para o uso dessa energia limpa e sustentável. O ramo de empresas que estão investindo em trabalhar com essa fonte natural está em crescimento, o que facilita a busca do cidadão interessado em realizar esse investimento. É notório que o aumento das contas de energia se tornou uma preocupação para a população e, por esse motivo, investir na instalação do sistema fotovoltaico se apresenta como ótima decisão.

\section{REFERÊNCIAS}

ABSOLAR - ASSOCIAÇÃO BRASILEIRA DE ENERGIA SOLAR FOTOVOLTAICA. Disponível em: http://www.aneel.gov.br/documents/656877/16832773/4++ABSOLAR+GD+Solar+Fotovoltaica.pdf/f0d41ea4-4bba-8cf8-fb02-b864dc83c293. Acesso em: 10 mai. 2021

ANEEL - AGÊNCIA NACIONAL DE ENERGIA ELÉTRICA. Disponível em: http://www2.aneel.gov.br/aplicacoes/atlas/pdf/03-Energia_Solar(3).pdf. Acesso em: 10 mai. 2021.

BARRETO, W. F.; VEIGA, A. J. P. ENERGIA SOLAR: UM FUTURO SUSTENTÁVEL PARA VITÓRIA DA CONQUISTA - BA. GEOPAUTA, v. 3, n. 2, p. 77-95, 2019. Disponível em: https://www.redalyc.org/journal/5743/574362250008/html/. Acesso em: 10 out. 2021

BASSO, L. H. et al. Análise de um sistema de aquecimento de água para residências rurais, utilizando energia solar. Engenharia Agrícola, v. 30, p. 14-21, 2010. Disponível em: https://www.scielo.br/j/eagri/a/JJP99G9hWkFVhGygByKLpJt/?lang=pt\&format=pdf. Acesso em: 01 jun. 2021. 
BLUESOL. Sistemas fotovoltaicos isolados. Disponível em: https://blog.bluesol.com.br/diferenca-sistemas-fotovoltaicos-conectado-a-rede-eisolaodos. Acesso em: 09 mai. 2021.

CRESESB. Manual de Engenharia para Sistemas Fotovoltaicos. CEPEL CRESESB: Rio de Janeiro, 2014.

HECK, V. V. Análise de sistemas de aproveitamento de energia solar para edificações residenciais. In: VII Congresso Brasileiro de Energia Solar, 2018.

INCENTIVE SOLAR. RADIAÇÃO SOLAR: o que tem a ver com a energia solar? Disponível em: https://incentivesolar.com.br/radiacao-solar/. Acesso em: 11 out. 2021

MENDES, H; OLIVEIRA, L. S. Viabilidade e instalação de energia solar distribuída em uma residência unifamiliar. 2019. Trabalho de Conclusão de Curso (Graduação em Engenharia) - Universidade Unievangélica, Ceres, GO, 2019.

MILIANO, R. A.; SILVA, L. Estudo da viabilidade econômica da implantação de um sistema fotovoltaico conectado à rede de energia elétrica em uma residência unifamiliar. $2019 . \quad$ Disponível em: http://repositorio.fucamp.com.br/bitstream/FUCAMP/520/1/Estudoviabilidadeeconomi ca.pdf_.Acesso em: 10 out. 2021.

MOGAWER, T.; SOUZA, T. M. de. Sistemas Solar de Aquecimento de Água para residências populares. Guaratinguetá , São Paulo: Centro de Energias Renováveis - Unesp, 2004.

PORTAL SOLAR. Energia solar fotovoltaica atinge 1 gigawatt em geração distribuída no Brasil. Disponível em: https://www.portalsolar.com.br/blogsolar/energia-solar/energia-solar-fotovoltaica-atinge-1-gigawatt-em-geracaodistribuida-no-brasil.html. Acesso em: 10 out. 2021.

SÁ, V. de. S. Estudo de viabilidade de utilização de sistema de geração fotovoltaica conectado à rede no Brasil. 2016. 42 f. Monografia (Graduação em

Disponível em: https://www.nucleodoconhecimento.com.br/engenharia-civil/viabilidade-deaplicacao 
Engenharia Civil) - Escola de Minas, Universidade Federal de Ouro Preto, Ouro Preto, 2016.

SILVA, A. S.; SOUZA, F. M. C. Viabilidade econômica da energia solar. In: Encontro Nacional de Engenharia de Produção, XVIII ENEGEP, 1998.

STROM BRASIL. Sistemas on grid e off grid. Disponível em: https://www.strombrasil.com.br/sistemas-on-grid-e-off-grid/. Acesso em: 09 mai. 2021.

Enviado: Novembro, 2021.

Aprovado: Dezembro, 2021. 